\title{
Acessibilidade e Teatro: a presença das pessoas com deficiência visual como provocação
}

\begin{abstract}
Accessibility and Theatre: the presence of people with visual impairment as provocation
\end{abstract}

Jefferson Fernandes Alves ${ }^{1}$ 


\section{Resumo}

O presente trabalho procura refletir sobre a acessibilidade, considerando a interface Acessibilidade/Teatro, empreendendo dois movimentos argumentativos. No primeiro deles, enfocamos estudos que se dedicam à audiodescrição do espetáculo de teatro, tendo como referência a recepção teatral, na perspectiva da formação de espectadores. No segundo, tratamos da acessibilidade nos contextos educacionais, considerando o teatro e seu ensino, cuja linha de argumentação assumida em relação à recepção teatral ajuda-nos a pensar não apenas na adaptação curricular do ensino do teatro, mas na perspectiva de sua reinvenção por intermédio da potência epistêmica, estética e política da acessibilidade e da presença, na escola, de crianças e de jovens com deficiência visual.

Palavras-chave: Audiodescrição; recepção teatral; ensino de teatro; deficiência visual.

\section{Abstract}

The present work seeks to reflect upon the accessibility, considering the interface Accessibility/Theatre employing two argumentative movements. In the first of those, we focus on studies dedicated to the audio description of the spectacle of theatre, having as reference the theatrical reception, in the perspective of formation of spectators. In the second part, we treat with accessibility in the educational contexts, considering the theatre and its teaching, whose line of argument assumed in relation to the theatrical reception help us to think not only on the curricular adaptation of the teaching of theatre, but on the perspective of its reinvention through epistemic potency, aesthetics and politics of accessibility and of presence, in school, of children and youths with visual impairment.

Keywords: Audio description; theatrical reception; theatre teaching; visual impairment

\footnotetext{
1 Prof. Dr. Programas de Pós-Graduação em Artes Cênicas e Educação da Universidade Federal do Rio Grande do Norte (UFRN). Pesquisa e orienta na interface, educação, acessibilidade, deficiência e teatro.jfa_alves@msn.com>
} 
As reflexões que empreendemos em torno da Audiodescrição (AD) e do Teatro, orbitando no campo da recepção teatral, procuram deslocar-se um pouco das abordagens dos estudos da tradução e da tecnologia assistiva, nas quais se enquadrariam a AD. Sem desconsiderar tais vinculações, sobretudo, no que se refere à tradução audiovisual acessível, optamos por enfatizá-la como um procedimento mediador, tendo como referência as provocações de Desgranges (2011) sobre mediação teatral, bem como, as ideias de Bakhtin (2003) sobre o caráter dialógico da linguagem.Dessa maneira, procuramos entender a audiodescrição, sem perder de vista a dimensão semiótica da palavra e da imagem, no delineamento de entre-lugares que atam as interações comunicacionais dos seres humanos.

Essa perspectiva empresta relevo à dimensão relacional da própria natureza sígnica, cuja existência pressupõe cadeias ou redes semióticas, configuradas pelo próprio caráter responsivo dos signos, em um movimento infinito dos processos humanos de atribuição de sentidos. Considerando esse viés, compreendemos a audiodescrição como uma resposta ao espetáculo teatral com o propósito de que a pessoa com deficiência visual possa assumir um posicionamento responsivo em relação ao espetáculo acessível.

Essa ideia de entre-lugar nos acompanha nas ponderações sobre teatro e audiodescrição por entender que a compreensão desta arte como "encontro", no qual olhamos e somos olhados (Guénoun, 2003) ou participamos de uma experiência artística de transcendência da solidão (Grotowski, 1992), desencadeia a presença do espectador na liminaridade entre o real e a fábula, tendo como referência uma matriz visuocêntrica que ratifica o caráter etimológico do teatro como essencialmente vinculado à percepção visual de quem assiste.

Nesse caso, pensamos na audiodescrição como um procedimento que não apenas ocupa o entre-lugar como também o dilata, na medida em que as visualidades da cena são apreensíveis por parte das pessoas com deficiência visual, sugerindo outros arranjos semióticos e estéticos que provoquem o exercício de olhar e ser olhado ou mesmo a experiência da transcendência da solidão, sem necessariamente, fazer uso da percepção visual.

Por sua vez, esclarecemos que a participação das pessoas com deficiência visual no encontro teatral, considerando a perspectiva que assumimos, não deve se orientar pelas cosmovisões da perda e da falta, referentes à cegueira e à baixa visão, as quais concorrem para o asilamento cultural, em decorrência, sobretudo, da pretensa inacessibilidade das práticas artísticas assentadas na visualidade.

Desse modo, pensamos que todas as pessoas devem ir ao teatro para se submeterem à experiência do encontro com o outro e consigo mesmo, a partir das provocações cênicas, as quais possam nos lançar em um exercício da convivialidade como potência de problematização e de reinvenção das formas de sermos e estarmos no mundo. 


\section{A cena teatral provocando e sendo provocada}

A perspectiva de participação das pessoas com deficiência como espectador, ou mesmo como atuante da cena,pode contribuir para o encontro e o confronto entre mundos, entre centros axiológicos, entre formas de apreender e de compreender o outro, levando em conta, sobretudo, a possibilidade de perturbar a normalidade como paradigma social. É preciso, no entanto, assinalar que essa presença em cena ou na plateia não deve ser interpretada pelo eixo do extraordinário ou da superação, pois, no nosso entendimento, tais clivagens concorrem para a reiteração do preconceito pela via inversa, na medida em que a exaltação da individualidade dos feitos artísticos e estéticos expiam a própria culpabilidade dos interditos e estigmatização social em relação à essas pessoas.

O extraordinário é o papel da arte em provocar o ordinário da vida, de tal maneira que se expor para o outro e perceber o outro são dimensões alteritárias do ser humano que se constrói nas refrações simbólicas. Nesse aspecto, a arte teatral pode ser entendida como a arte da provocação, conforme nos lembra Grotowski (1992, p. 19):

\footnotetext{
Por que nos preocupamos com arte? Para cruzar fronteiras, vencer limitações, preencher o nosso vazio - para nos realizar. Não se trata de uma condição, mas de um processo através do qual o que é obscuro em nós torna-se paulatinamente claro. Nesta luta com a nossa verdade interior, neste esforço em rasgar a máscara da vida, o teatro, com sua extraordinária perceptibilidade, sempre pareceu um lugar de provocação. É capaz de desafiar o próprio teatro e o público, violando estereótipos convencionais de visão, sentimento e julgamento - de forma mais dissonante, porque sensibilizada pela respiração do organismo humano, pelo corpo e pelos impulsos interiores.
}

As ponderações de Grotowski (1992) auxiliam nossas reflexões sobre a perspectiva da presença das pessoas com deficiência no teatro. Na ótica da recepção teatral, essa presença pode provocar o próprio teatro não apenas pelo fato de que o coletivo artístico ou aqueles que respondem pela produção do espetáculo têm que atender ao item da acessibilidade do edital, mas na dilatação da própria concepção de espectador, na medida em que segmentos invisibilizados começam a fruir a cena.

Ademais, se a experiência cênica se orienta pela afetação de quem a assiste, tais espectadores afetam o próprio teatro, uma vez que os arranjos tradutórios inerentes aos processos de acessibilidade, especialmente em relação aos surdos e às pessoas com deficiência visual, geram um outro tipo de encontro em relação à cena que diz respeito aos profissionais de LIBRAS e de audiodescrição com aqueles que se ocupam do espetáculo. Tal encontro, geralmente, suscita questões em torno do respeito e da preservação do desenho cênico, da negociação dos sentidos construídos pelo roteiro da tradução (AD ou LIBRAS), da localização da cabine para a audiodescrição ou, em outros casos, a posição do audiodescritor.

Tais questões corroboram com o fato de que a emergência desses espectadores expandem as áreas e os agentes envolvidos com o engendramento da cena, revelando um outro entre-lugar (entre o espaço cênico e o espaço arquitetônico), gerador de negociações e arranjos em favor da constituição da cena acessível, como, 
por exemplo, o posicionamento do tradutor/intérprete de LIBRAS no palco (ou ao lado deste), o fato de que é preciso ter um desenho de luz para o mesmo e a possibilidade dessa presença "perturbar"a atuação do elenco e a apreensão da cena por aqueles que não são surdos.

Outra perspectiva de provocação à arte teatral, diz respeito à realização da acessibilidade da cena teatral articulada ou inserida no próprio processo criativo ou mesmo na própria concepção cênica do espetáculo. Considerando a audiodescrição, essas possibilidades de afetação da cena já vêm sendo experimentadas no Brasil.

Um dos primeiros estudos de mestrado assentado na interface Audiodescrição/ Teatro foi realizado por Andreza Nóbrega (2012), a qual desenvolveu o processo de acessibilidade na proporção que montava o espetáculo "Nem Sempre Lila" (2011), com seu grupo teatral "Quadro de Cena" (Recife/PE), orientado pela perspectiva do processo colaborativo. Acumulando os papeis de pesquisadora, de atriz e de audiodescritora, Nóbrega assumiu o viés de uma pesquisa intervenção, centrada na montagem do espetáculo, vinculando-a ao desenvolvimento da audiodescrição correspondente.

Ao passo que o espetáculo tomava forma com dramaturgia, sonoplastia, indumentária, cenografia, iluminação e maquiagem, paralelamente era elaborado o roteiro áudio-descritivo, com os registros de marca da atriz-pesquisadora e, posteriormente, com a presença de outra áudio-descritora nos ensaios, que realizava ajustes, discussão com membros da equipe, resultando na versão final. (Nóbrega, 2012, p. 148)

Assumindo uma vertente nominativa da audiodescrição como "áudio-descrição", Nóbrega (2012) centra seus esforços reflexivos na vertente da recepção teatral, na medida em que se preocupa com a contribuição da AD na apropriação da cena teatral por parte das pessoas com deficiência visual, constituindo-se, para alguns dos participantes da pesquisa, nas primeiras experiências de acesso ao teatro na condição de espectador:

Mel - Pra mim foi a primeira vez e eu gostaria muito de poder frequentar mais vezes.

Est - Olha, eu comecei a ir ao teatro depois que eu fiquei cega, queeu não conhecia eu não tinha possibilidade, mas depois que eu fiqueicega e depois que vocês vieram a dar essa chance pra gente, essaoportunidade. Foi muito válida. A minha primeira vez foi lá emJerusalém, né? Ali em Caruaru. Eu assisti Nova Jerusalém, lá. Foimuito legal eu achei muito bom. Depois nós fomos ao Parque...

Juc - [...] Eu comecei a vim ao teatro depois da áudio-descrição. Antes eu não vinha ao teatro. Foi a duas que participei até hoje.

Juc - Espetáculo. O São João de Caruaru, no Camarote daacessibilidade, foi a primeira vez que eu tive acesso a áudio-descrição, depois no festival de inverno em Garanhuns, uma peça deteatro e essa é a terceira vez. (NÓBREGA, 2012, p. 216)

Outra iniciativa, nessa perspectiva, de construção simultânea da cena e de sua acessibilidade, foi empreendida pelo Grupo Bandeira das Artes (Fortaleza/CE), do qual participam Bruna Leão e Klístenes Braga, os quais, além de atriz/ator, são pesquisadores e profissionais da área da acessibilidade, com ênfase na audiodescrição. Trata-se do 
espetáculo infantil "Miralu e a Luneta Encantada" (2013). E, mais recentemente, registramos uma construção cênica que não apenas considerou a acessibilidade em LIBRAS e em audiodescrição desde a concepção da proposta, como também, incorporou-as à dramaturgia e à encenação do espetáculo. Trata-se do espetáculo "É Proibido Miar", da MA Companhia de Teatro, Dança e Assemelhados (Porto Alegre/RS), de tal maneira que a cena é orquestrada, considerando a manifestação poeticamente endógena da Língua de Sinais e da audiodescrição, a partir das investigações das possibilidades cênicas que tais procedimentos de acessibilidade poderiam suscitar.

Dessa forma, parafraseando Grotowski, o próprio teatro é desafiado na perspectiva de violar seus estereótipos, sentimentos e julgamentos em relação a determinados segmentos sociais que não se enquadram nos parâmetros de normalidade e que, historicamente, não usufruíam da cena teatral, como os cegos e os surdos. De outra maneira, o teatro (como a arte, de modo geral), simultaneamente, pode desafiar os procedimentos tradutórios de acessibilidade a investigarem as respectivas potências poéticas dessas traduções, a partir do contato (e do contágio) com a linguagem artística e sua respectiva obra, como, no caso em questão, o espetáculo teatral.

Nesse sentido, Josélia Neves, audiodescritora e pesquisadora da área de acessibilidade, a partir da abordagem dos estudos da tradução, vem insistindo na consideração de uma audiodescrição orientada poeticamente que dê conta da interlocução com o campo das artes, tomando como referência, entre outras coisas, a questão básica da incapacidade da palavra contemplar, plenamente, a experiência de fruição estética, notadamente, das obras orientadas pela visualidade. Em decorrência disto, Neves (2012) vem propondo uma perspectiva de transcriação artística, designada por ela de soundpainting, dirigida, especialmente, para o universo das artes visuais, e tomando como referência uma abordagem multissensorial que ultrapasse o eixo da informação, em favor da expressividade e das provocações subjetivas e emocionais advindas da experiência estética com a obra.

Voltando para a interface Audiodescrição/Teatro, verificamos que esse desafio constituído na fricção inerente à essa interface e que suscita a afetação dos processos tradutórios pelas peculiaridades sintáticas do campo do teatro, sugere possibilidades promissoras de investigação artística e científica.

Nessa direção, podemos assinalar o estudo de mestrado de Nascimento (2017), o qual, assumindo a dimensão mediadora da audiodescrição, procura dilatar a fruição do espetáculo teatral acessível, por meio do desenvolvimento de oficinas, a partir de parâmetros metodológicos propostos por Desgranges (2011) no que se refere à formação do espectador.

Considerando o espetáculo De Janelas e Luas, monólogo protagonizado por Mayra Montenegro, Nascimento (2017) empreende o processo de audiodescrição da peça, articulando-o com o planejamento de oficinas, fundamentado nos exercícios de desmontagens (Desgranges, 2011), as quais foram realizadas no contexto de uma escola estadual, da cidade de Natal, contemplando uma turma do 1 Ano do Ensino Médio, na qual havia dois jovens com deficiência visual. Dessa maneira, toda a turma assistiu ao espetáculo, apresentado no auditório da escola, cuja experiência de fruição foi expandida por conta das oficinas que antecederam e sucederam a apresentação. 
Para Nascimento (2017, p. 137): "Se o teatro se constitui como a arte do encontro, a audiodescrição como tradução intersemiótica se constitui em uma força mediadora que amplia a comunhão cênica, no aqui e no agora da manifestação teatral."

Ainda se orientando pela expansão da experiência estética, agregado ao agenciamento da audiodescrição, Nascimento (2017), após a apresentação do espetáculo de "Janelas e Luas", convidou toda a assistência para ver e tocar no figurino da atriz e nos objetos de cena. Para tanto, organizou a exposição, fazendo uso de quatro suportes de madeira, nos quais se posicionavam cestos de vime com almofadas cobertas por tecido na cor vinho. Em cada cesto, estavam expostos os objetos de cena para serem apreciados pelo tato, com a mediação da palavra. Além disso, no circuito expositivo, apresentou o figurino da atriz em um manequim de fibra de vidro, para ampliar a interação tátil dos participantes, sobretudo, dos jovens com deficiência visual. No processo de apreciação, a pesquisadora, a atriz e dois auxiliares de pesquisa atuaram na mediação da leitura dos materiais em exposição.

Tais experiências hápticas no contexto da recepção teatral de espetáculos acessíveis para pessoas com deficiência visual já são experimentadas por algumas iniciativas de acessibilidade da cena teatral brasileira, tanto antes como depois do espetáculo, muito embora que só tenham sido objeto de reflexão na dissertação de Nascimento (2017). No âmbito das orientações de acessibilidade para o teatro, Neves (2011, p. 23) é categórica ao assinalar que tal procedimento deve ser engendrado antes da apresentação teatral:

\footnotetext{
Para uma maior fruição do espectáculo, é comum levar os espectadores cegos a visitar o palco e os bastidores, permitindo-lhes explorar cenários, adereços e guarda-roupa. Havendo o acordo dos actores, aproveita-se esta visita aos bastidores, que se dá obrigatoriamente antes de o espectáculo começar, para que as pessoas cegas conheçam as pessoas que vão dar corpo às personagens, passando, deste modo, a conhecer as suas vozes e, muitas vezes, o seu aspecto físico.
}

Essas orientações foram consideradas pelas iniciativas de audiodescrição de vários espetáculos teatrais, em Portugal, cujos estudos (Santiago, 2015; Violante, 2015) pontuaram como importantes no processo de aproximação estética dos espectadores com deficiência visual das obras cênicas, destacando-se uma apropriação verbo-corporal do palco, a exploração dos objetos cênicos e o contato com os atores, cuja interação anterior permite-lhes a investigação do figurino e a identificação vocal que lhes auxiliará na relação com os personagens.

Por conseguinte, os procedimentos de acessibilidade na área da recepção teatral configuram-se como desencadeadores de leitura acessível da cena, por meio da escuta e do toque, concorrentes para processos de formação do espectador com deficiência visual. Além disso, apresentam-se como promissoras para se pensar práticas pedagógicas acessíveis no contexto do ensino de teatro. 


\section{A acessibilidade e o ensino de teatro: alguns desafios considerando o contexto escolar}

Se no campo da produção da cena, o delineamento da imagem do espectador por parte da encenação, usualmente, não considera a fruição da pessoa com deficiência visual, o qual só se revela, posteriormente, por meio da acessibilidade do espetáculo, no contexto das práticas pedagógicas em cenários escolares, a forma como tais práticas são orquestradas pelo paradigma da normalidade, comumente, só são tensionadas quando se constata a presença de alunos com deficiência na sala de aula.

Verifica-se uma angústia generalizada dos professores de todas as áreas do conhecimento escolar, os quais argumentam "despreparo" para os processos de ensino-aprendizagem, gerando, quase sempre, ações pedagógicas que discriminam a participação escolar desses alunos, por meio de atividades que os separam da turma. Muitos desses profissionais procuram, individualmente, cursos de formação continuada compensatórios, com o propósito de contemplar novos saberes e novas experiências que considerem tais alunos como sujeitos estéticos e epistêmicos.

Isso põe em destaque a urgência de se considerar a reestruturação dos cursos de licenciaturas, de modo geral, e o de teatro, em particular, na perspectiva de assinalar, curricularmente, saberes e práticas que levem em conta a rasura do paradigma da normalidade que subjaz à formação de professores, o qual fundamenta o delineamento de um aluno ideal, abstrato e descontextualizado socialmente. De outra parte, é importante a configuração de ações articuladas na área de formação continuada que suscite uma interlocução duradoura entre a universidade e a escola, tendo como referência a problematização da realidade concreta da escola e os saberes e experiências docentes.

Essa interlocução, inclusive, na área de teatro, pode engendrar relações de trocas de saberes com os egressos, pavimentando cenários formativos que enfeixem iniciativas de pesquisa, tendo como referência as práticas pedagógicas no contexto da escola, orientando-se por processos de reinvenção, considerando as provocações estéticas e culturais da presença dos alunos com deficiência. Essa perspectiva nos remete às reflexões de Evgen Bavcar (2003) sobre a cegueira, deslocando-a da estreiteza explicativa da restrição sensorial para interpretá-la como potência epistêmica e estética que orienta outras formas de perceber e de estar no mundo, as quais suscitam outros olhares (tiresianos) que se erguem no encontro liminar entre vidência e não vidência, claridade e escuridão.

Essa perspectiva de ir além da falta e da restrição, no nosso entendimento, deve se orientar pelo enfrentamento de cosmovisões que atravessam a vida social e escolar, as quais procuram enquadrar as pessoas com deficiência pelo eixo da falta e da pena, próprios dos modelos explicativos caritativo e biomédico. Nesse sentido, o modelo social de enfoque da deficiência, evidencia seu aspecto de construção social, deslocando-a do caráter funcional e individual para assinalar que as restrições e impedimentos que acompanham a própria caracterização da deficiência são orquestradas socialmente. (Cf. Lanna Júnior, 2010).

Além disso, as abordagens pedagógicas no ensino de teatro (ou nas demais artes) devem evitar os enfoques de "normalização" desses alunos que, a despeito da 
flexibilização curricular e dos procedimentos de acessibilidade, tomam como referência padrões de normalidade corporal e cognitiva. Nesse caso, a consideração dos múltiplos itinerários culturais, das múltiplas formas de manifestação corporal, das múltiplas maneiras de perceber e de aprender podem nos ajudar na problematização dos encantos tradicionais da homogeneização das práticas pedagógicas.

Ademais, no esforço de superação da invisibilidade de tais alunos no contexto escolar, a partir do engendramento de práticas pedagógicas que deflagrem encontros alteritários que mobilizem toda a turma, devemos ultrapassar o enfoque instrumental do teatro como meio para abordar a temática da inclusão e da deficiência, sobretudo, em proposições de cenas e de espetáculos, concebidas para sensibilizar, por exemplo, a escola e os pais.

A abordagem temática não pode sobrepor à abordagem curricular do teatro como campo do conhecimento escolar, como linguagem, passível de ser apropriada por todos os alunos. Nesse caso, as dimensões sintáticas e semânticas da arte teatral devem ser investigadas pelas crianças e pelos jovens em contexto escolar, orientando-se pelo fundamento artístico do tensionamento simbólico do real, podendo, inclusive, contemplar as questões em torno da deficiência.

Nessa mesma direção, a fruição e a criação por parte de alunos com deficiência devem ser assumidas curricularmente como intrínseca ao exercício da arte do encontro, cuja presença desses alunos, ao expandir cultural e sensorialmente a própria dimensão alteritária desse encontro, pode subsidiar a problematização da emergência do preconceito que se aloja, inversamente, na "exaltação" e na ideia da "superação", conforme chamamos a atenção mais acima, quando tratamos da recepção teatral.

Por conseguinte, reiteramos que a ênfase na ação heroica individual, pode empanar os direitos culturais e educacionais de todos aqueles que não se enquadram nos padrões de normalidade, uma vez que o esforço e o envolvimento pessoal estão diretamente relacionados às oportunidades sociais e escolares que devem ser proporcionadas a todos pelas políticas públicas. Assim, de outra maneira, as participações dos alunos com deficiência, fruindo a cena ou atuando nela,podem provocar, esteticamente, espantos e deslocamentos que não apenas friccionam as questões temáticas, mas que afetam o teatro como arte e como componente curricular.

Retomando as ponderações expostas sobre a audiodescrição e a recepção teatral, podemos assinalar que o desenvolvimento de jogos, de oficinas e de procedimentos de criação e de fruição teatral não deve se contentar apenas na adaptação curricular das práticas pedagógicas para contemplar as crianças e jovens com deficiência, como partícipes das propostas dirigidas para toda turma. Se, mais atrás, chamávamos a atenção de que a presença das pessoas com deficiência como espectadores afetava a própria configuração da cena, em decorrência do processo de acessibilidade do espetáculo, a presença e o protagonismo requerido no contexto de sala de aula dessas pessoas, ao friccionar o ensino de teatro, nos desafia no sentido de desenvolver processos e práticas pedagógicas que superem as conotações de reatividade, em favor de proposições que investiguem, a partir de distintos pontos de vista, de formas diversas de perceber e de apreender o outro e a externalidade do mundo, os saberes inerentes à arte teatral para além do paradigma da normalidade. 
Assim, podemos aprender com as outras formas de agenciamento semiótico da palavra, da imagem e do corpo que procuram desenhar arranjos de acessibilidade nas esferas do audível, do toque e da gestualidade em favor daqueles que interpretam e expressam o mundo de outras maneiras. Essa aprendizagem pode nos auxiliar na reinvenção das formas que concebemos e realizamos a práticas pedagógicas no ensino de Teatro.

Levando em conta que tais perspectivas procuram rasurar esse paradigma da normalidade, as outras formas de interpretação e de expressão podem reordenar a repartição curricular do sensível como dimensão estético-política que determina o que é comum e o que específico para a participação daqueles que aprendem (cf. Rancière, 2009).

Dessa maneira, a mobilização intersemiótica da palavra e da imagem, conforme se manifesta na audiodescrição e o agenciamento da exploração tátil que se apresenta nos processos de dilatação da mediação teatral, devem, ao mesmo tempo que considerem as singularidades sensoriais das pessoas com deficiência, constituírem-se como provocação epistêmica e alteritária para contemplar todos que aprendem, tendo como horizonte de sentido a capacidade provocadora da arte em relação à vida, em relação ao ser humano e em relação à si mesma.

\section{Referências}

BAKHTIN, Mikhail. Estética da Criação Verbal. Rio de Janeiro: Martins Fontes, 2003.

BAVCAR, Evgen. Um outro olhar. In: TESLLER, Élida; BANDEIRA, João. Memória do Brasil. São Paulo: Cosac \&Naify, 2003, p. 135-142.

DESGRANGES, Flávio. A pedagogia do teatro: provocação e dialogismo. 3. ed.- São Paulo: Editora Hucitec: Edições Mandacaru, 2011.

GUÉNOUN, Denis. A exibição das palavras: uma idéia (política) do teatro. Rio de Janeiro: Teatro do Pequeno Gesto, 2003.

GROTOWSKI, Jerzy. Em busca de um teatro pobre. 4a. Ed. Rio de Janeiro: Civilização Brasileira, 1992.

LANNA JÚNIOR, Mário Cléber Martins (Comp.). História do Movimento Político das Pessoas com Deficiência no Brasil. - Brasília: Secretaria de Direitos Humanos. Secretaria Nacional de Promoção dos Direitos da Pessoa com Deficiência, 2010.

NASCIMENTO, Anna Karolina Alves do. Audiodescrição e mediação teatral: o processo de acessibilidade do espetáculo De Janelas e Luas. Natal, 2017, 165f. Dissertação (Mestrado). Programa de Pós-Graduação em Educação. Universidade Federal do Rio Grande do Norte, 2017. 
NÓBREGA, Andreza. Caminhos para a inclusão: uma reflexão sobre audiodescrição no teatro infanto-juvenil. Recife, 2012. 240f. Dissertação (Mestrado). Programa de Pós-Graduação em Educação.Universidade Federal de Pernambuco, 2012.

NEVES, Josélia. Guia de audiodescrição - imagens que se ouvem. Leiria/Pt: Instituto Nacional de Reabilitação e Instituto Politécnico de Leiria, 2011.

NEVES, Josélia. Multi-sensory approaches to (audio)describing the Visual Arts. Multidisciplinarityin Audiovisual. MonTI 4. Universidad de Alicante/ES, 2012: 277-293.

RANCIÈRE, Jacques. A partilha do sensível. São Paulo: Editora 34, 2009.

SANTIAGO, Sandra M.S.A. Audiodescrição em contexto de teatro em Portugal. Porto, 2015, 136f. Dissertação (Mestrado). Mestrado em Tradução e Serviços Linguísticos. Faculdade de Letras da Universidade do Porto, 2015.

VIOLANTE, Marta Sofia S. de Sousa. Audiodescrição para pessoas com incapacidade visual em peças de teatro. Leiria/Pt, 2015, 190f. Dissertação (Mestrado). Mestrado em Comunicação Acessível. Escola Superior de Educação e Ciências Sociais. Instituto Politécnico de Leiria, 2015.

Recebido em: 19/07/2018

Aprovado em: 22/01/2019 